\title{
ANALISIS KEMAMPUAN BERPIKIR LOGIS MATEMATIS PADA SISWA SEKOLAH MENENGAH ATAS (SMA) BERDASARKAN POLA SIDIK JARI ARCHES
}

\author{
Sri Devi Wulandari ${ }^{\mathrm{a}}$ \\ ${ }^{a}$ Program Studi Pendidikan Matematika, FKIP UN PGRI Kediri \\ Jl. K.H Ahmad Dahlan No.76, Mojoroto, Kec. Mojoroto, Kota Kediri, Jawa Timur 64112, \\ srideviwulandari321@gmail.com
}

\begin{abstract}
Abstrak
Turunan merupakan salah satu bab dalam pembelajaran matematika yang di dalamnya terdapat sub aplikasi turunan. Aplikasi turunan merupakan contoh materi permasalahan dalam kehidupan sehari-hari yang diselesaikan dengan menggunkan ilmu matematika. Salah satu contohnya adalah dalam dunia industri, dimana suatu pabrik bisa menghitung pengeluaran yang minimal untuk memperoleh keuntungan yang besar. Dengan begitu terlihat bahwa aplikasi turunan sangat penting untuk dipelajari. Namun kenyataannya siswa masih kesulitan dalam mengerjakan soal yang diberikan. Hal tersebut terlihat pada saat siswa diberikan soal masih belum bisa mengerjakan. Kemampuan siswa dalam menyelesaikan soal berbeda-beda. Pada dasarnya masalah tersebut dapat diketahui sejak dini, salah satu caranya dengan melakukan tes sidik jari. Dari hasil pekerjaan siswa, peneliti terispirasi untuk menganalisis kemampuan berpikir logis matematis siswa dalam menyelesaikan soal, hal ini dilakukan untuk mencari solusi pembelajaran selanjutnya sehingga siswa bisa memahami materi aplikasi turunan yang sangat bermanfaat dalam kehidupan sehari-hari. Penelitian ini menggunakan pendekatan penelitian kualitatif dengan jenis penelitian kualitatif deskriptif, yaitu dengan cara menganalisis data yang ada untuk memperoleh informasi mengenai kemampuan berpikir logis matematis siswa dalam menyelesaikan soal aplikasi turunan berdasarkan pola sidik jari. Hasil penelitian ini adalah siswa dengan pola sidik jari Arches mampu memenuhi 2 indikator kemampuan berpikir logis matematis yaitu mampu mengubah ke dalam bentuk matematika dan dapat menjadikan pernyataan secara tertulis, lisan dan gambar.
\end{abstract}

Kata kunci : Berpikir logis matematis, pola sidik jari, aplikasi turunan.

\begin{abstract}
Derivatives are one of the chapters in mathematics learning in which there are derivative sub-applications. Derived applications are examples of material problems in everyday life that are solved by using mathematics. One example is in the industrial world, where a factory can calculate a minimum expenditure to get a big profit. That way it can be seen that derivative applications are very important to learn. But in reality students are still having difficulty working on the questions given. This can be seen when the students are given the problem still cannot work. Students' ability to solve questions is different. Basically, the problem can be known early on, one of the ways to do fingerprint tests. From the results of the work of students, researchers are inspired to analyze the students' mathematical logical thinking skills in solving problems, this is done to look for further learning solutions so students can understand derivative application material that is very useful in everyday life. This study uses a qualitative research approach with descriptive qualitative research, namely by analyzing existing data to obtain information about students' mathematical logical thinking skills in solving derivative application questions
\end{abstract}


based on fingerprint patterns. The results of this study were students with archetype fingerprint patterns were able to meet 2 indicators of mathematical logical thinking ability that is able to change into mathematical sentences in writing, oral, and image and able to provide evidence or reason for the correcness of the solution.

Keywords: mathematical logical thinking, fingerprint patterns, derivative applications.

\section{PENDAHULUAN}

Menurut Rokhayati (2010), pelajaran matematika membina kemampuan peserta didik dalam memahami konsep matematika dengan menggunakan penalaran, menyelesaikan masalah, mengkomunikasikan gagasan dan memiliki sikap menghargai terhadap matematika. Oleh karena itu para pakar pendidikan selalu berupaya melakukan penelitian agar pelajaran matematika dapat dipahami oleh siswa.

Berdasarkan latihan soal pada materi integral dan turunan yang diberikan guru sebelum pembelajaran di akhiri terlihat bahwa siswa masih kesulitan dalam mengerjakan soal tersebut, hal itu terlihat dari cara siswa mengerjakan soal tes yang bekerjasama dengan teman sekelasnya. Walaupun nilai yang diperoleh diatas ratarata akan tetapi cara memperolehnya bukan hasil pekerjaannya sendiri. Peristiwa tersebut diperoleh peneliti saat melaksanakan studi pendahuluan di SMA kelas XI. Walaupun bekerjasama nilai yang didapat juga mengalami perbedaan. Siswa yang mendapat nilai bagus pada beberapa materi, tetapi kurang pandai pada suatu materi tertentu. Misalnya siswa yang pandai dalam geometri belum tentu pandai dalam materi aljabar,aritmetika sosial, dan materi lain yang berkaitan dengan kemampuan analisis. Dari permasalahan tersebut peneliti menyimpulkan bahwa hal tersebut terjadi karena perbedaan pada kemampuan dasar matematika siswa.

Pada dasarnya masalah tersebut dapat diketahui sejak dini, salah satu cara yang dapat dilakukan adalah dengan melakukan tes sidik jari. Setiono \& Edi (2009) mengatakan bahwa dari tes pola sidik jari, kecerdasan majemuk tersebut sudah diurutkan dari yang paling kuat ke yang paling lemah.

Gardner (2003) menyatakan teori yang ditemukannya, yaitu kecerdasan minimal yang dimiliki seseorang meliputi delapan kemampuan intelektual yang dikenal dengan teori multiple intellegences. Diantaranya kecerdasan linguistik, kecerdasan logis matematis, kecerdasan spasial, kecerdasan kinestetik-tubuh, kecerdasan music, kecerdasan interpersonal, kecerdasan intrapersonal, kecerdasan natural. Secara teoritis, kecerdasan logis matematis sebagai salah satu dari kecerdasan majemuk (multiple intellegence) 
bisa didefinisikan sebagai kapasitas seseorang untuk berpikir secara logis dalam memecahkan kasus atau permasalahan dan melakukan perhitungan matematis.

Dalam menyelesaikan masalah matematika, setiap orang memiliki cara dan gaya berpikir yang berbeda-beda karena tidak semua orang memiliki kemampuan berpikir logis matematis yang sama. Berpikir logis matematis diperlukan dalam menyelesaikan permaslahan matematika. berdasarkan uraian diatas maka peneliti tertarik untuk meneliti tentang "analisis kemampuan berpikir logis matematis pada siswa sekolah menengah atas (SMA) berdasarkan pola sidik jari arches". Agar suatu penelitian dapat terlaksana dengan baik dan sesuai sasaran, maka suatu penelitian harus memiliki tujuan. Tujuan dari penelitian ini adalah mendeskripsikan kemampuan berpikir logis matematis siswa berdasarkan pola sidik jari berjenis Arches.

\section{METODE PENELITIAN}

Pendekatan penelitian yang akan digunakan oleh peneliti adalah pendekatan penelitian kualitatif. Jenis penelitian yang akan digunakan dalam penelitian ini adalah penelitian kualitatif deskriptif, yaitu dengan cara menganalisis data yang ada untuk memperoleh informasi mengenai kemampuan berpikir logis matematis siwa untuk memecahkan soal pada materi Turunan berdasarkan pola sidik jari.
Informasi atau data tersebut dapat diperoleh dari hasil tes dan wawancara subjek penelitian.

Indikator yang digunakan dalam penelitian ini yaitu:

1. Menjadikan pernyataan matematika secara lisan, tertulis, dan gambar.

2. Memberi bukti atau alasan terhadap kebenaran solusi.

3. Menarik kesimpulan dari persoalan.

Tahapan penelitian dalam penelitian yang akan dilakukan adalah sebagai berikut:

1. Tahap Pendahuluan

Mencari masalah, mengkonsultasikan kepada dosen, mencari sumber yang mendukung, menyusun rencana penelitian, meminta izin tempat penelitian, dan menyiapkan peralatan penelitian.

2. Tahap Perencanaan

Mengatur jadwal penelitian, menyusun instrumen, memvalidasi instrumen, membuat pedoman wawancara, menyiapkan buku catatan, menyiapkan alat dokumentasi.

3. Tahap Pelaksanaan Penelitian

Mengatur jam penelitian, tes sidikjari, tes soal, wawancara, mengkonfirmasi guru mata pelajaran, mengumpulkan semua data.

4. Tahap Penyelesaian

Menganalisis data, mendeskripsikan kesimpulan, mengkonsultasikan kepada dosen. 
Tempat yang digunakan dalam penelitian adalah jenjang SMA sederajad kelas XI. Subjek yang digunakan dalam penelitian adalah siswa SMA kelas XI yang dipilih berdasarkan pertimbagan guru, siswa yang dipilih memiliki pola sidik jari arches dan memiliki komunikatif. Mekanisme dalam menentukan subjek adalah sebagai berikut yang terlihat pada gambar 3.1

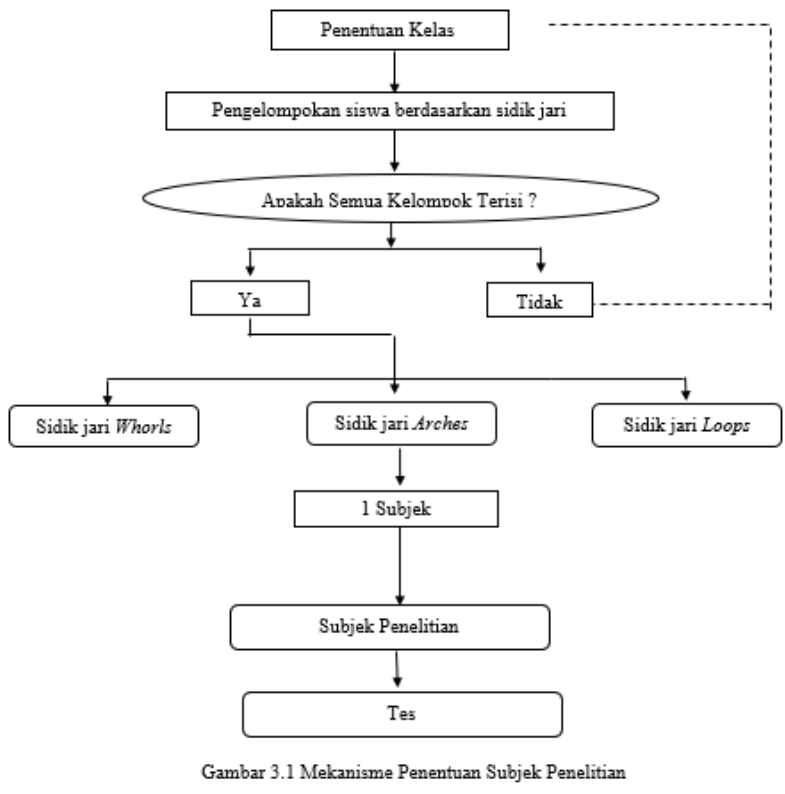

Dalam penelitian ini ada 2 jenis instrumen yaitu instrument utama dan instrument bantu. Instrumen utama adalah peneliti itu sendiri, dan instrumen bantu yang berupa tes sidik jari, tes soal, wawancara dan dokumentasi. Ada tiga aktivitas yang dilakukan dalam analisis data penelitian kualitatif, yaitu : data reduction, data display, dan conclusion drawing atau verification.

1. Data Reduction (Reduksi data)
Reduksi data dilakukan dengan cara memberi kode pada hasil wawancara. Dalam transkrip penelitian ini kode yang digunakan adalah $\mathrm{P}$ dan SA dimana $\mathrm{P}$ menyatakan penanya, dan SA menyatakan subyek dari kelompok kategori bersidik jari Arches.

2. Data Display (Penyajian data)

Penyajian data dilakukan dengan mengurutkan data berdasarkan waktu setiap tindakan peserta didik dalam menyelesaiakan tes. Melalui penyajian data tersebut, data akan lebih mudah untuk dipahami dan dapat dengan mudah dalam menarik kesimpulan.

3. Conclusion Drawing (Penarikan Kesimpulan)

Langkah terakhir adalah penarikan kesimpulan, yaitu memberikan makna dan penjelasan terhadap hasil penyajian data. Kesimpulan akan kredibel jika data yang diperoleh juga kredibel, untuk menguji kredibelitas data maka digunakan triangulasi. Jenis triangulasi yang akan digunakan adalah triangulasi Teknik.

Untuk menguji keabsahan temuan, maka dalam penelitian yang akan dilakukan peneliti perlu melakukan uji keabsahan temuan di antaranya uji credibility, dependability, dan confirmability (Sugiyono, 2014). 
HASIL DAN PEMBAHASAN

Tahap penelitian kualitatif dalam deskripsi hasil penelitian ini akan disajikan menjadi beberapa bagian, diantaranya mulai dari penentuan subjek dari masing-masing kategori, analisis data, dan hasil penelitian tentang proses kemampuan berpikir logis matematis peserta didik pada materi aplikasi turunan berdasarkan pola sidik jari arches. Presentase subjek dapat dilihat pada Tabel 1:

Tabel 1. Persentase Subjek Penelitian

\begin{tabular}{lcc}
$\begin{array}{l}\text { Jenis sidik } \\
\text { jari }\end{array}$ & $\begin{array}{c}\text { Banyak } \\
\text { siswa }\end{array}$ & $\begin{array}{c}\text { Persentase } \\
(\boldsymbol{\%})\end{array}$ \\
\hline WHORLS & 7 & 28 \\
ARCHES & 13 & 52 \\
LOOPS & 5 & 20 \\
\hline
\end{tabular}

Berdasarkan Tabel 1 diperoleh siswa dengan sidik jari whorls sebesar 28\%, siswa dengan sidik jari arches sebesar 52\%, dan siswa dengan sidik jari loops sebesar $20 \%$. Peneliti memilih siswa dengan perolehan presentase terbesar dengan jumlah 1 subjek atas pertimbangan guru, siswa yang dipilih adalah siswa yang komunikatif.

Triangulasi yang digunakan adalah triangulasi teknik.

a. Tujuan

Untuk menguji kredibilitas data yang diperoleh dan hasil penelitian yang lebih kredibel/ dapat dipercaya.

b. Proses

Dalam proses triangulasi teknik dilakukan dengan cara mencheck data kepada sumber yang sama dengan teknik yang berbeda, teknik yang digunakan dalam penelitian ini yaitu tes tulis, wawancara, observasi, dan dokumentasi.

Untuk memperjelas triangulasi teknik dengan menggunakan metode tes dan wawancara, maka dapat dilihat dari hasil rincian masing-masing indikator sebagai berikut. Hasil penelitian dapat dilihat pada Tabel 2.

Berdasarkan uraian Tabel 2, pembahasan dari subjek yang mewakili sidik jari Arches dapat dilihat bahwa penelitian ini secara umum dari ketiga indikator, subjek dapat memenuhi dua indikator yaitu indikator menjadikan pernyataan matematika secara lisan, tertulis, gambar. Dan memberikan bukti atau alasan terhadap kebenaran solusi.

Pada indikator menjadikan pernyataan matematika secara lisan, tertulis, dan gambar subjek mampu menyebutkan tentang apa saja yang diketahui dan ditanyakan pada soal secara lisan tetapi subjek tidak menuliskan dilembar jawaban. Hal ini sesuai dengan teori yang disampaikan oleh Wardhani (2008:14) yaitu dapat menjelaskan dan menetapkan hal-hal yang diketahui dan ditanyakan. Sehingga dapat disimpulkan bahwa pada tahap ini subjek menunjukkan kemampuan dalam menyelesaikan soal walaupun hasilnya masih kurang tepat. Hal ini sesuai dengan teori yang disampaikan oleh Wardhani (2008) yaitu terkait memberikan bukti atau alasan terhadap kebenaran solusi. 
Tabel 2. Deskripsi kemampuan berpikir logis matematis siswa dengan pola sidik jari Arches

\begin{tabular}{|c|c|c|c|}
\hline Indikator & Wawancara & Tes & Validitas \\
\hline $\begin{array}{l}\text { Menjadikan } \\
\text { pernyataan } \\
\text { matematika } \\
\text { secara lisan, } \\
\text { tertulis, dan } \\
\text { gambar. }\end{array}$ & $\begin{array}{l}\text { 1.Subjek dapat } \\
\text { mengubah soal } \\
\text { cerita dalam } \\
\text { kalimat } \\
\text { matematika } \\
\text { 2. Subjek bisa } \\
\text { menjadikan dalam } \\
\text { bentuk gambar }\end{array}$ & $\begin{array}{l}\text { bari gambar terlihat } \\
\text { bahwa subjek } \\
\text { mampu mengubah } \\
\text { dalam ram bentuk } \\
\text { kalimat matematika } \\
\text { dan gambar. }\end{array}$ & Valid \\
\hline $\begin{array}{lr}\text { Memberi } & \text { bukti } \\
\text { atau } & \text { alasan } \\
\text { terhadap } & \\
\text { kebenaran } & \text { solusi. }\end{array}$ & $\begin{array}{l}\text { 1.Subjek dapat } \\
\text { menjelaskan hasil } \\
\text { pekerjaannya }\end{array}$ & $\begin{array}{l}\text { Dari gambar } \\
\text { bahwa terlihat } \\
\text { menuliskan proses } \\
\text { dalam menjawab } \\
\text { soal. }\end{array}$ & Valid \\
\hline $\begin{array}{l}\text { Menarik } \\
\text { kesimpulan dari } \\
\text { persoalan. }\end{array}$ & $\begin{array}{l}\text { 1.Subjek } \\
\text { kebingungan } \\
\text { dalam menarik } \\
\text { kesimpulan }\end{array}$ & $\begin{array}{l}\text { Dari gambar terlihat } \\
\text { bahwa siswa tidak } \\
\text { menyimpilkan hasil } \\
\text { pekerjaannya }\end{array}$ & Valid \\
\hline
\end{tabular}

Pada indikator menarik indikator ketiga, hal ini terbukti bahwa kesimpulan dari persoalan subjek menunjukkan rasa kebingungan dalam menarik kesimpulan dengan baik dari permasalahan yang telah diselesaikan, subjek juga tidak menuliskan kesimpulan pada lembar jawabannya. Jadi dapat disimpulkan bahwa subjek tidak mampu dalam mencapai subjek masih pada saat wawancara dan tidak menuliskannya pada lembar jawaban. Hal ini sesuai dengan pendapat Shadiq (2004) bahwa telah terjadi penarikan kesimpulan dari beberapa fakta yang telah diketahui oleh peserta didik.

\section{KESIMPULAN DAN SARAN}

Berdasarkan hasil analisis dan pembahasan sebelumnya, peneliti membuat kesimpulan tentang analisis kemampuan

berpikir logis matematis siswa berdasarkan pola sidik jari Arches dengan tiga siklus yaitu memilih subjek penelitian, memberi tes tulis kepada subjek, dan mengklarifikasi subjek dengan wawancara, yaitu secara 
umum dari ketiga indikator, subjek dapat memenuhi dua indikator yaitu indikator menjadikan pernyataan matematika secara lisan, tertulis, gambar dan memberikan bukti atau alasan terhadap kebenaran solusi.

Berdasarkan hasil penelitian dan kesimpulan, peneliti mengemukakan saran sebagai berikut :

1. Bagi Peserta Didik

Melalui hasil penelitian ini dapat dijadikan sebagai acuan untuk memperluas dan mengasah tahapantahapan proses berpikir logis peserta didik dalam menyelesaikan soal matematika berdasarkan pola sidik jari yang dimiliknya.

2. Bagi Guru

Hasil penelitian dapat digunakan guru sebagai informasi tentang kemampuan berpikir logis matematis berdasarkan pola sidik jari dalam menyelesaikan soal matematika yang nantinya dapat digunakan sebagai dasar untuk memilih dan memilah model pembelajaran yang tepat untuk peserta didik.

3. Bagi Peneliti Selanjutnya

Melalui hasil penelitian ini diharapkan dapat dijadikan referensi dalam melakukan penelitian selanjutnya dengan memperluas dan memperdalam ruang lingkup penelitian.

\section{DAFTAR PUSTAKA}

Gardner, H. R. (2003). Kecerdasan Majemuk. Batam: Interaksa.

Setiono, W., \& Edi, A. (2009). Apakah Anda Ingin Menemukan Potensi Unggul Anak Anda Sejak Dini. Jakarta: Grasindo.

Sugiyono. (2014). Metode Penelitian Pendidikan (Pendekatan Kuantitatif, Kualitatif, dan $R \& D)$ ). Bandung: Alfabeta.

Wardhani, Sri. 2008. Analisis SI dan SKL Mata Pelajaran Matematika SMP/MTs Untuk Optimalisasi Tujuan Mata Pelajaran Matematika. Yogyakarta: Pusat Perbukuan dan Pemberdayaan Pendidik Dan Tenaga Kependidikan Matematika.

Rokhayati, N. (2010). Peningkatan Penguasaan Konsep Matematika Melalui Model Pembelajaran Guinded Discovery-Inquiry pada Siswa Kelas VII SMPN 1 Sleman. Yogyakarta: Fakultas Matematika dan Ilmu Pengetahuan Alam Universitas Negeri Yogyakarta.

Shadiq, F. 2004. Pemecahan Masalah, Penalaran, dan Komunikasi. Makalah disampaikan pada Diklat Instruktur/Pengembang

MatematikaSMA Jenjang Dasar di PPPG Matematika Tanggal 6 s.d. 19 Agustus 2004. Yogyakarta: Depdiknas Dasar dan Menengah Pusat Pengembangan Penataran Guru (PPPG) Matematika Yogyakarta. 